
кровотечений

1 - Городская клиническая больница им. С.П.Боткина Департамента здравоохранения г. Москвы: 125284, Москва, 2-й Боткинский пр., 5; 2 - ФГБУ "НИИ общей реаниматологии им. В.А.Неговского" РАМН: 107031, Москва, ул. Петровка, 25, стр. 2

\author{
V.N.Yakovlev, Yu.V.Marchenkov, I.Yu.Korzheva, V.G.Alekseev, V.V.Moroz
}

\title{
Modern methods of diagnosis and treatment of pulmonary hemorrage
}

Key words: pulmonary hemorrage, bronchoscopic hemostasis, endovascular catheter embolisation of bronchial arteries. Ключевые слова: легочное кровотечение, бронхоскопический гемостаз, эндоваскулярная катетерная эмболизация бронхиальных артерий.

Частота легочных кровотечений (ЛК) составляет 1-4\% общего количества кровотечений. Летальность этого осложнения достигает 50-80 \% [1, 2]. Летальные исходы при ЛК, даже небольшого объема, обусловлены, главным образом, не кровопотерей, а асфиксией. Причинами ЛК могут быть десятки заболеваний различных органов и систем. Наиболее часто ЛК встречается при заболеваниях органов дыхания, поэтому эти больные, как правило, госпитализируются в пульмонологические отделения. Именно поэтому врач-пульмонолог должен четко ориентироваться в современных подходах к диагностике и лечению ЛК в зависимости от его вида и степени. Если степень ЛК можно предположить, основываясь на клинических методах обследования, то диагностика причины ЛК и дальнейшая тактика лечения всегда вызывает большие трудности [3, 4].

\section{Классификация ЛК}

Степени ЛК в зависимости от интенсивности кровопотери [5]:

І степень - кровохарканье:

- Іа - 50 мл в сутки;

- І Іб - 50-200 мл в сутки;

- Ів - 200-500 мл в сутки.

II степень - массивное ЛК:

- ІІа - 30-200 мл в час;

- ІІб - 200-500 мл в час.

III степень - профузное ЛК:

- ІІІа - 100 мл одномоментно;

- ІІІб - > 100 мл одномоментно + обструкция трахеобронхиального дерева, асфиксия.

В зависимости от объема кровопотери выделяют [5, 6]:

- малое ЛК - 50-100 мл в сутки;

- среднее ЛК - 100-500 мл в сутки;

- тяжелое ЛК - > 500 мл в сутки;

- особо тяжелое (обильное) ЛК - кровопотеря $>500$ мл, возникает одномоментно или в течение короткого промежутка времени.
Важное практическое значение имеет классификация, учитывающая не только количественные критерии кровопотери, но и реакцию организма на неe [7].

І степень кровотечения - потеря $\leq 300$ мл в сутки крови с кашлем.

1. Однократное ЛК:

- скрытое;

- явное.

2. Многократное ЛК:

- скрытое;

- явное.

II степень кровотечения - кровопотеря $\leq 700$ мл в сутки.

1. Однократное ЛК:

- со снижением артериального давления (АД) и гемоглобина;

- без снижения АД и гемоглобина.

2. Многократное ЛК:

- со снижением АД и гемоглобина;

- без снижения АД и гемоглобина.

III степень кровотечения - кровопотеря > 700 мл в сутки:

- при массивном ЛК учитывается кратность повторения эпизодов выделения крови, изменения АД, лейкоцитарной формулы крови;

- при молниеносном ЛК с летальным исходом обильное (> 500 мл) кровотечение, возникающее одномоментно или в течение короткого промежутка времени.

Клинические варианты ЛК [8]:

- асфиксическое (молниеносное);

- непрерывное или ложно рецидивирующее;

- нарастающее;

- состоявшееся (закончившееся);

- рецидивирующее.

Установить изначальный вариант ЛК достаточно трудно, т. к. они легко трансформируются друг в друга, особенно на фоне многокомпонентной гемостатической терапии. Кровохарканье, малые ЛК, даже 
повторные, редко непосредственно угрожают жизни больных. Наиболее опасно усиление их темпа и интенсивности [9].

\section{Патогенез ЛК}

Основные факторы патогенеза ЛК [10]:

- морфологические (сосудистые);

- гемодинамические;

- коагулопатические.

Сущность морфологических факторов заключается в том, что в зонах хронического воспаления и пневмосклероза формируются тонкостенные сосудистые сплетения, напоминающие гемангиомы, стенки которых не содержат эластических волокон. Эти сплетения легко разрываются при повышении АД и резких перепадах внутригрудного давления. Важно и непосредственное поражение воспалительным или опухолевым процессом стенки сосудов, в результате чего развиваются аррозивные кровотечения [6].

Гемодинамический фактор выражается в наличии при различных заболеваниях легких и сердца повышенного в 3-5 раз выше нормы давления в малом круге кровообращения, а также подъема в силу различных причин АД, который приводит к разрыву измененной стенки сосуда. Легочная гипертензия является важнейшим негативным фактором для больного с ЛК [11].
Нарушения свертывающей системы крови проявляются в первоначальной гиперкоагуляции с последующим длительным повышением активности фибринолитических факторов. Это препятствует образованию полноценного тромба в дефекте сосуда и становится одним из дополнительных факторов, определяющих своеобразную готовность организма больного к рецидиву кровотечения. Таким образом, ЛК могут формировать целую систему "порочных кругов" взаимного отягощения. Поэтому оказание помощи больным с ЛК должно осуществляться только в условиях стационаров, где имеются возможности использования современных методов диагностики, консервативного и хирургического лечения этого крайне тяжелого осложнения различных заболеваний, травм и состояний.

\section{Диагностика ЛК}

Клиническая картина ЛК состоит из симптомокомплекса общей кровопотери, признаков наружного кровотечения и проявлений легочно-сердечной недостаточности, обусловленной как основным заболеванием, явившимся причиной кровотечения, так и обструкцией трахеобронхиального дерева излившейся кровью. Из анамнеза почти всегда удается выяснить наличие какого-либо легочного заболевания. Однако возможны случаи, когда ЛК является пер-

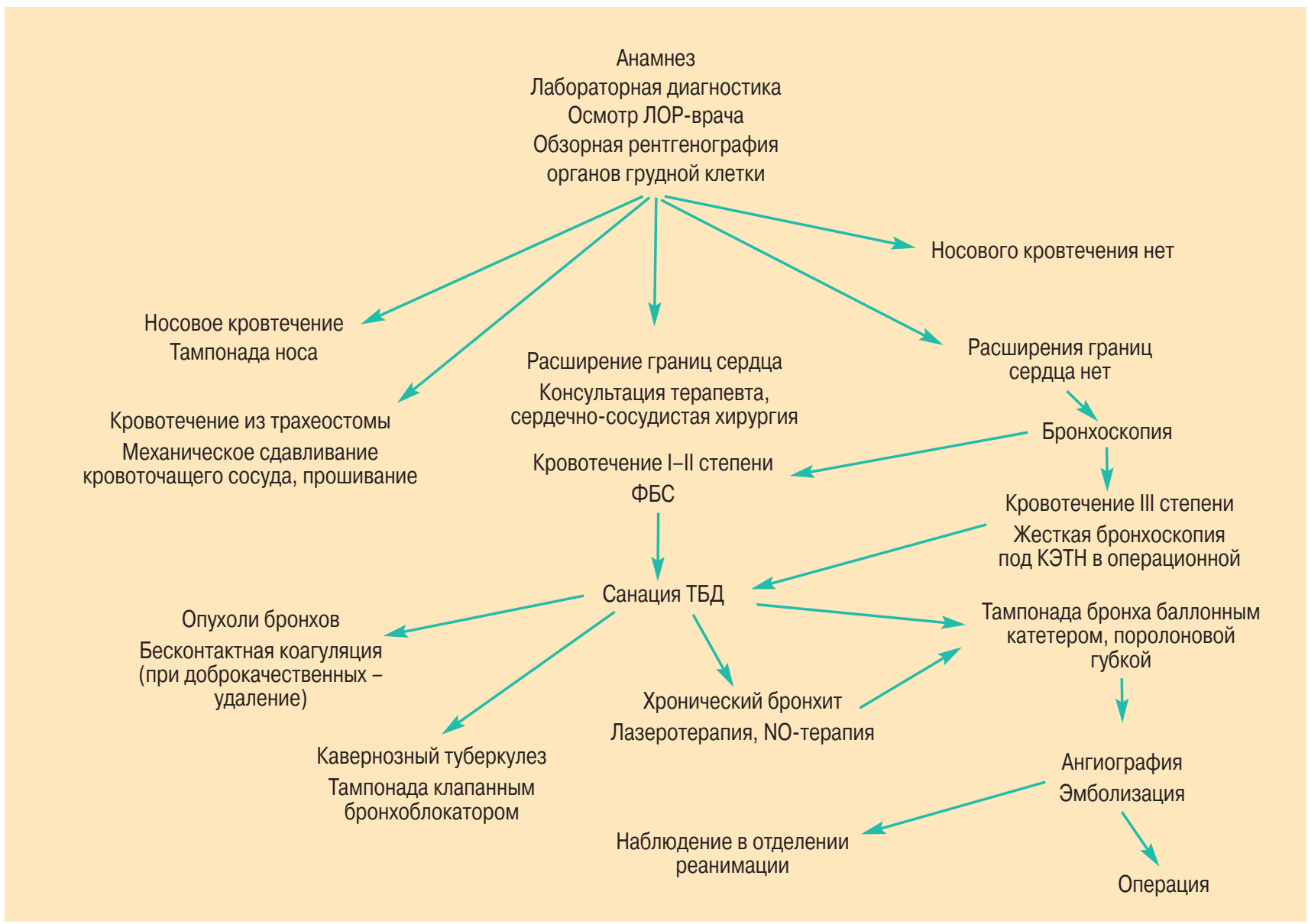

Рис. 1. Лечебно-диагностический алгоритм при ЛК

Примечание: ФБС - фибробронхоскопия; КЭТН -комбинированный эндотрахеальный наркоз; ТБД - трахеобронхиальное дерево. 
вым проявлением основного заболевания. Необходимо отметить, что у пациентов старшей возрастной группы наиболее вероятной причиной легочного кровохарканья и ЛК является опухоль легкого. На 2-м месте по частоте стоят бронхоэктатическая болезнь и хронический атрофический бронхит. Другие заболевания, при которых наблюдаются ЛК (туберкулезные каверны, абсцесс легкого, аневризма легочного сосуда, ранение или травма легкого и т. п.), в практической работе встречаются значительно реже.

При этом общепринятые физикальные приемы врачебного обследования часто дают возможность получить весьма важную информацию, во многом определяюшую содержание, последовательность и объем проведения более сложных, специальных инструментальных исследований.

Наиболее информативным методом исследования и диагностики ЛК является эндоскопический, позволяющий не только установить сам факт ЛК и его вероятный источник, но и осуществить весь комплекс мероприятий, направленных на его остановку. Рентгенологические исследования (рентгеноскопия, рентгенография, компьютерная томография - КТ) позволяют лишь выявить наличие в легочной ткани патологического процесса, являющегося возможной причиной ЛК. Данные рентгенологического обследования дают возможность вывить характер изменений в легких, установить источник кровотечения и его местоположение в 65-75\% наблюдений. На рентгенограммах можно увидеть опухолевый узел, каверны, ателектаз, тени инфильтратов, мицетомы. Однако нередко у больных с ЛК никакой патологии при рентгенологическом исследовании не выявляется. В этих случаях важную роль играет КТ органов грудной клетки, которая оказывает существенную помощь в диагностике, позволяя выявить наличие опухолевых образований как в легочной ткани, так и в просвете верхних дыхательных путей, деструктивные изменения в легочной ткани, а также бронхоэктазии, патологию лимфатических узлов средостения и их взаимосвязь с бронхиальной стенкой, состояние сосудов малого и большого кругов кровообращения [11]. Для уточнения источника кровотечения используют также ангиопульмонографию или селективную ангиографию бронхиальных артерий.

В целях диагностики и своевременного и правильного оказания помощи больным с ЛК необходимо следующее (рис. 1):

- установить сам факт ЛК, т. е. провести дифференциальную диагностику между ЛК и желудочнокишечным кровотечением, кровотечением при заболеваниях ЛОР-органов и полости рта;

- установить локализацию и источник ЛК;

- установить возможный характер и распространенность патологического процесса в легких;

- оценить объем кровопотери и степень гиповолемии;

- провести анализ основных биохимических показателей и коагулограмму.
Принципы лечения ЛК [1, 12-14]

Все лечебно-диагностические мероприятия должны быть направлены на остановку ЛК, стабилизацию состояния больного и выигрыш во времени для решения вопроса о дальнейшей тактике. При этом ведение больного и лечебно-диагностический алгоритм должен соответствовать степени ЛК и состоянию пациента (рис. 2). В случае массивного ЛК больной должен немедленно госпитализироваться в отделение реанимации и интенсивной терапии, где проводится необходимый комплекс лечебно-диагностических мероприятий.

\section{Предупреждение асфиксии}

Для предупреждения асфиксии предпринимаются следующие меры:

- восстановление проходимости дыхательных путей, в т. ч. интубация трахеи, аспирация излившейся крови;

- возвышенное положение тела;

- положение больного - на больном боку;

- нормализация газообмена: оксигенотерапия или искусственная вентиляция легких при наличии острой дыхательной недостаточности (гипоксемия, гиперкапния, респираторный ацидоз).

Массивное ЛК является показанием для эндобронхиальной интубации [14]. Должна осуществляться именно эндобронхиальная, а не эндотрахеальная интубация, чтобы предотвратить затекание крови в интактное легкое [15]. Раздельная интубация бронхов производится с помощью специальных эндобронхиальных трубок (Карленса, Уайта, Робертшоу) [16].

\section{Остановка кровотечения}

\section{Эндоскопические методы}

Среди всех эндоскопических методов исследования бронхоскопия занимает ведущее место, являясь не только одним из первых диагностических методов, но и важнейшим и эффективным способом лечения больных с различной патологией органов дыхания. Показанием к лечебным эндоскопическим исследованиям является состоявшееся или продолжающееся ЛК. Используются следующие виды лечебных вмешательств:

- санационная бронхоскопия;

- терапия лазерным излучением;

- NO-терапия;

- региональная лимфатическая терапия;

- электрокоагуляция;

- радиоволновые эндоскопические вмешательства;

- извлечение инородных тел;

- окклюзия бронхов.

В последнее время ведущим методом остановки кровотечения является клапанная бронхоблокация [17, 18]. Также применяется бронхоскопия с окклюзией бронха тугим марлевым тампоном, гемостатической или поролоновой губкой, баллоном Фогарти, а также электрокоагуляцией или аппликацией полимерами. Как правило, поиск источника 
кровотечения начинают с проведения бронхоскопии. Ригидная бронхоскопия считается более предпочтительной по сравнению с ФБС, т. к. позволяет увеличить обзор, эффективно выполнить эндобронхиальный туалет и удалить крупные сгустки крови. В то же время ФБС может оказаться лучшей мерой при локализации источника кровотечения в верхних долях легких. Также применяется комбинация 2 бронхоскопических методов, когда фибробронхоскоп проводится через канал ригидного бронхоскопа. Источник

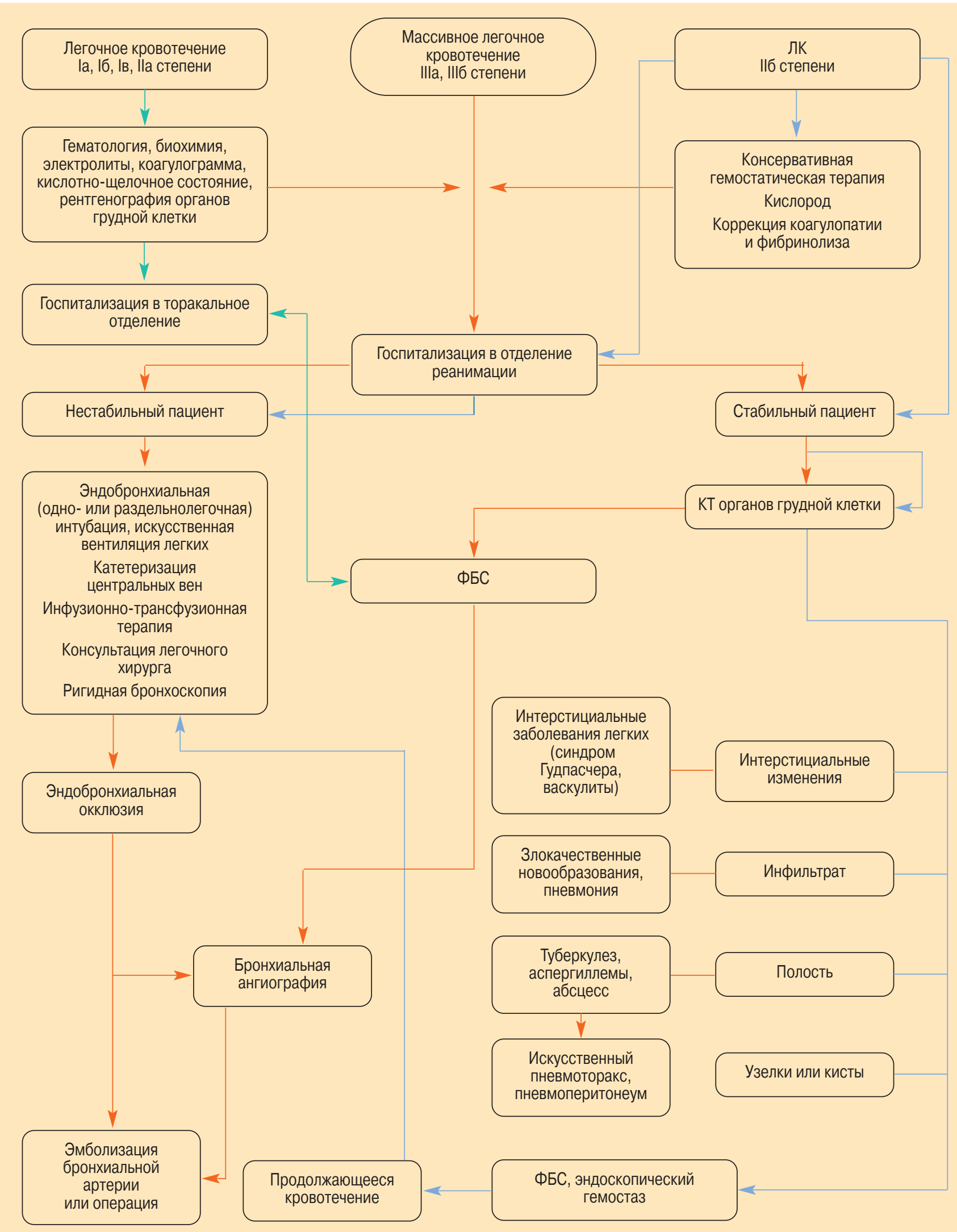

Рис. 2. Алгоритм лечебно-диагностических мероприятий в зависимости от степени ЛК 
кровотечения при бронхоскопии выявляют в $90 \%$ случаев при продолжающемся кровотечении и в $50 \%-$ после его прекращения [19-21]. Во время бронхоскопии возможно проведение интубации главного бронха непораженного легкого для предотвращения аспирации крови и обеспечения вентиляции. В эКстренных ситуациях проводится тампонада главного бронха пораженной стороны катетером с баллончиком (типа Фогарти), выполняются эндобронхиальные инстилляции раствором адреналина через ирригационный катетер. Эффективен лаваж кровоточащего сегментарного бронха холодным физиологическим раствором, растворами фибриногена или тромбина. При остановленном ЛК, устранении гипоксии и гиперкапнии и стабильной гемодинамике целесообразно проведение аспирационной бронхоскопии и бронхиального лаважа для вымывания кровяных сгустков [22].

\section{Консервативное медикаментозное лечение}

Консервативное лечение ЛК может быть высокоэффективным, а по своей сути является органосохраняющей технологией [23]. Общая направленность предпринимаемых действий во всех случаях требует соблюдения ряда положений, учитывающих патогенез ЛК, и включает в себя следующее:

- обеспечение или восстановление проходимости дыхательных путей при их обструкции излившейся кровью или патологическим отделяемым из пораженного легкого;

- подавление длительных эпизодов мучительного кашля, чаще всего препятствующего остановке кровотечения;

- медикаментозное снижение давления в системе малого круга кровообращения;

- повышение свертываемости крови и предотвращение патологического фибринолиза;

- борьбу с анемией;

- уменьшение интоксикации и перифокального воспаления в легком;

- повышение регенераторной способности и нормализация жизненно важных функций организма больных;

Наблюдающийся при ЛК упорный кашель не следует полностью подавлять, чтобы не препятствовать откашливанию излившейся в бронхи крови и не создавать условий для возникновения аспирационной пневмонии. С другой стороны, противокашлевая терапия необходима, т. к. внутрилегочное давление при кашлевом толчке повышается в несколько раз по сравнению с обычным, что приводит к дополнительному повреждению ткани в области кровотечения и усиливает его. В качестве противокашлевых средств используются наркотические средства: прежде всего, кодеин, гидрокодона фосфат, этилморфина гидрохлорид или текодин.

При эмоциональном возбуждении больного хороший эффект оказывают седативные средства (валериана, корвалол, валокордин) и транквилизаторы (мепротан, триоксазин, хлордиазепоксид, диазепам или седуксен). Кислородотерапия через назальный катетер должна быть постоянной при потоке кислорода 3-5 л в минуту.

В дальнейшем тактика лечения определяется причинами, вызывающими ЛК. Если кровотечение связано с высоким давлением в малом круге кровообращения, то необходимо это давление снизить. Считается, что $>90$ \% летальных исходов при ЛК связано с легочной гипертензией. В связи с этим важнейшим патогенетическим методом лечения больных с ЛК является искусственно управляемая гипотония [24].

Методы гипотензивной терапии. Наиболее часто для создания управляемой гипотензии используют введение ганглиоблокаторов (арфонада, имехина, пентамина, бензогексония) под постоянным мониторингом АД. Многими исследователями отмечается быстрое проявление их гемостатического действия [6, $25,26]$. Однако одним из основных механизмов действия ганглиоблокаторов является их депрессорное влияние на кровообращение в целом, выражающееся в торможении передачи вазоконстрикторной импульсации из сосудистого центра, снижении секреции катехоламинов а также в прямом влиянии некоторых ганглиоблокаторов на сосудистую стенку. Эти механизмы могут способствовать переходу управляемой гипотензии в неуправляемую, которая, в конечном счете, может привести к серьезным осложнениям. Кроме того, при массивных кровотечениях с гиповолемией и артериальной гипотензией управляемая гипотония неприменима.

В настоящее время в лечении ЛК для индуцирования гипотензии, кроме ганглиоблокаторов, используется ряд следующих препаратов, обладающих прямым сосудорасширяющим действием [27]:

1. Венозные вазодилататоры (гидралазин, изофлюран, нитропруссид натрия, нитроглицерин, аденозин и аденозинтрифосфат), которые расслабляют гладкомышечные клетки в венах, артериях и артериолах, увеличивают венозную емкость и снижают венозный возврат к сердцу, тем самым понижая давление в малом круге кровообращения.

2. $\beta$-Адреноблокаторы, сосудорасширяющее действие которых может быть обусловлено одним из следующих основных механизмов или их сочетанием:

- выраженной внутренней адреномиметической активностью в отношении $\beta$-адренорецепторов сосудов (например, пиндолол и целипролол);

- сочетанием $\beta$ - и $\alpha$-адреноблокирующей активности (например, карведилол);

- высвобождением из эндотелиальных клеток оксида азота (небиволол);

- прямым сосудорасширяюшим действием.

Инфузионно-трансфузионная терапия. ЛК, вызывающее постгеморрагическую анемию, является показанием к заместительной трансфузии эритроцитной массы. Для устранения гиповолемии, возникшей после большой кровопотери, рекомендуется введение производных гидроксиэтилкрахмала и кристаллоидов. 
В связи с тем, что при ЛК быстро меняются различные характеристики (податливость легких, их кровенаполнение, сосудистое сопротивление, внутрилегочное и внутригрудное давление), высока опасность гиперинфузии кристаллоидными растворами. Это может привести к перегрузке левых отделов сердца, интерстициальному отеку и отеку легких. Во избежание этого инфузионная программа должна осуществляться медленно [28]. При кровопотере до $20 \%$ объема циркулирующей крови (ОЦК) гемотрансфузия вообще не требуется, и кровезамещение проводится коллоидными и кристаллоидными растворами в соотношении $1: 2$. В случае кровопотери $>20 \%$ ОЦК, в т. ч. при массивных кровопотерях, главной задачей являются не столько коррекция анемии, сколько компенсация ОЦК, необходимого для поддержания нормальной гемодинамики, и проведение мероприятий с целью предотвращения коагулопатии [29].

Коррекция факторов свертывания. В рамках консервативной терапии оказать действенное влияние на систему гемостаза при ЛК возможно при своевременной диагностике и наличии современных препаратов коррекции.

Рекомбинантный активированный фактор VII (эптаког- $\alpha$ (rFVIIa) - препараты НовоСэвен, Коагил VII), первоначально предложенный для предупреждения и купирования кровотечений у больных с ингибиторной формой гемофилии, в последующих многочисленных исследованиях показал себя универсальным гемостатическим средством при самых разнообразных спонтанных и послеоперационных геморрагиях [30, 31]. При ЛК начинать введение эптакога- $\alpha$ следует как можно быстрее после начала кровотечения. Препарат в дозе 90 мкг / кг массы тела вводится внутривенно струйно. Длительность лечения и интервал между введениями препарата определяются выраженностью кровотечения или характером хирургического вмешательства.

Еще один препарат, ускоряющий свертывание крови, - это синтетический аналог антидиуретического гормона - десмопрессин, стимулирующий высвобождение предшественника фактора фон Виллебранда (гликопротеина плазмы крови, играющего важную роль в гемостазе) и фактора VIII.

Свежезамороженная плазма содержит все плазменные факторы. В экстренных случаях кровотечения, когда нет времени для проведения обследования пациента и выяснения причин, их вызвавших, несколько доз данного препарата крови может сохранить пациенту жизнь и остановить кровотечение. Уровень тромбоцитопении < 50 тыс. требует переливания тромбоцитарной массы. Также при ЛК применяется криопреципитат (концентрированный фактор VIII ) и PPSB - препарат, содержащий факторы IX, X, VII, II свертывающей системы, концентрация которых в 6-10 раз больше, чем в плазме здоровых доноров. Значительно медленнее действует витамин K и его синтетические аналоги, поскольку их действие опосредовано через синтез печенью факторов свертывания II, VII, IX, X.
Известными средствами для профилактики и остановки ЛК небольшой интенсивности являются стимуляторы адгезивно-агрегационной функции тромбоцитов - препараты кальция. Кальций непосредственно участвует в агрегации и адгезии тромбоцитов, а также способствует образованию тромбина и фибрина, то есть стимулирует образование как тромбоцитарных, так и фибринных тромбов [32].

Коррекция фибринолиза. Для коррекции повышенного фибринолиза при ЛК применяется широкий спектр лекарственных препаратов, включая эпсилонаминокапроновую и транексамовую кислоты, механизм действия которых заключается в ингибировании активации плазминогена и его превращение в плазмин. Эти препараты обладают специфическим местным и системным гемостатическим действием при кровотечениях, связанных с повышением фибринолиза, а также противоаллергическим и противовоспалительным действием - за счет подавления образования кининов и других активных пептидов [33]. Также при фибринолитических кровотечениях применяют апротинин (гордокс, контрикал, трасилол). Он блокирует калликреинкининовую систему, ингибирует как суммарную протеолитическую активность, так и активность отдельных протеолитических ферментов и является поливалентным ингибитором протеаз [34].

Необходимо помнить, что факторы свертывания и системные ингибиторы фибринолиза значительно увеличивают риск тромбоэмболических осложнений ввиду повышенного тромбообразования не только в зоне кровотечения, но и в отдаленных от источника кровотечения местах. Поэтому воздействовать на эту систему необходимо лишь при продолжающемся кровотечении, когда происходит потеря факторов свертывания, а также при нестабильном локальном гемостазе с высокой угрозой рецидива кровотечения на фоне развившейся гипокоагуляции и обязательном регулярном лабораторном контроле проводимой гемостатической терапии [35].

Для профилактики гемоаспирационной пневмонии гемостатическую терапию при острых воспалительных заболеваниях и свежих формах туберкулеза легких проводят одновременно с интенсивной противовоспалительной и противотуберкулезной терапией соответственно. Как правило, используют "зашищенные" полусинтетические пенициллины или цефалоспорины в комбинации с аминогликозидами [36, 37].

При развитии и прогрессировании аспирационной пневмонии антибактериальная терапия проводится с учетом возбудителя и его чувствительности к антибиотикам [38].

Комплексное применение описанных консервативных лечебных мероприятий, направленных на основную причину и ведущее патогенетическое звено возникающих ЛК и кровохарканья, позволяет остановить ЛК І-ІІ степени у 80-90 \% больных [39]. При массивных профузных ЛК консервативная терапия наименее эффективна. 


\section{Хирургическое лечение}

Хирургическое лечение включает в себя [40]:

- резекционные методы удаления участка легкого (всего легкого), в котором происходит патологический процесс, являющийся источником ЛК;

- перевязку легочной артерии или перевязку легочной артерии с пневмотомией и дренированием полости распада (паллиативные операции);

- временную окклюзию ветвей легочной артерии катетером с надувной манжетой от специального 2- или 3-просветного сердечного катетера (паллиативная операция);

- эндоваскулярную катетерную эмболизацию бронхиальных артерий.

Показания к катетерной эмболизации бронхиальных артерий [41]:

- неэффективность консервативной терапии ЛК, кровохарканье у больных с 2-сторонними воспалительными процессами, которым не показано хирургическое лечение по ряду причин;

- отсутствие грубых морфологических изменений, требующих резекции легкого, в основном у больных с очаговым пневмосклерозом;

- при массивных, опасных для жизни профузных кровотечениях как средство временной или постоянной его остановки.

Данный вид лечения проводится только во время кровотечения или не позже чем через 6-12 ч после его остановки. Успешного результата при эмболизации можно добиться в 77-100 \% случаев, поэтому в некоторых центрах этот метод рассматривается в качестве начального метода лечения при ЛК [42].

\section{Заключение}

ЛК, являясь тяжелым осложнением самых разных заболеваний, сопровождается высокой летальностью и требует комплексного многоуровневого подхода к их диагностике, лечению и профилактике с учетом этиологии и патогенеза в условиях специализированных отделений многопрофильного стационара.

В настоящее время тактика лечения ЛК предполагает последовательное или комбинированное использование многокомпонентной гемостатической терапии, эндоскопической окклюзии бронха, эндоваскулярной окклюзии бронхиальных артерий вне зависимости от этиологии легочного процесса, а также собственно оперативных методов лечения. Прогноз при ЛК зависит от основного заболевания, вида и выраженности кровотечения, своевременности окончательной остановки и наличия осложнений.

\section{Литература}

1. Jougon J., Ballester M., Delcambre F. et al. Massive hemoptysis: what place for medical and surgical treatment. Eur. J. Cardiothorac. Surg. 2002; 22: 345-351.

2. Козловский В.И., Карпицкий А.С., Шиленок Д.В. Кровохарканье и легочное кровотечение. Воен.-мед. журн. 1997; 6: 29-35.

3. Овчинников A.A. Кровохарканье и легочное кровотечение. Мед. помощь 2005; 5: 3-9.
4. Enting D., van der Werf T.S., Prins T.R. et al. Massive haemoptysis: primary care, diagnosis and treatment. Ned. Tijdschr. Geneesk. 2004; 148: 1582-1586.

5. Григорьев Е.Г. Диагностика и лечение легочного кровотечения: Автореф. дис. ... Д-ра мед. наук. Иркутск; 1990.

6. Перельман М.Н. Легочное кровотечение. Consilium Medicum 2006; 3: 88-92.

7. Стручков В.И., Недвецкая Л.М., Долина О.А., Бирюков Ю.В. Хронические нагноительные заболевания легких, осложненных кровотечением. М.: Медицина; 1985.

8. Киргинцев А.Г., Иванов А.В. Клиническая характеристика больных, экстренно госпитализированных с легочным кровотечением. Пробл. туб. 2000; 4: 28-32.

9. Unsal E., Koksal D., Cimen F. et al. Analysis of patients with hemoptysis in a reference hospital for chest diseases. Tuberk. Toraks. 2006; 54: 34-42.

10. Непомнящих Г.И., Непомнящих Л.М. Хронические воспалительные процессы в легких: прижизненная диагностика и прогноз. Арх. патол. 1990; 6: 6-9.

11. Чучалин А.Г. (ред.). Респираторная медицина. Руководство. М.: ГЭОТАР-Медиа; 2007; т. 1, 2.

12. Чернеховская Н.Е., Коржева И.Ю., Андреев В.П., Поваляев А.В. Легочные кровотечения. М.: Медпресс-информ; 2011.

13. Ong T.H., Eng P. Massive hemoptysis requiring intensive care. Intens. Care Med. 2003; 29: 317-320.

14. Габа Д.М., Фиш К.Дж., Хауард С.К. Критические состояния в анестезиологии. Пер. с англ. М.: Медицина; 2000.

15. Уткин М.М., Киргинцев А.Г., Свиридов С.В. и др. Интубация трахеи и бронхов при легочных кровотечениях. Анестезиол. и реаниматол. 2004; 2: 32-34.

16. Полушин Ю.С. (ред.). Руководство по анестезиологии и реаниматологии. СПб.: ЭЛБИ-СПб; 2004.

17. Левин А.В., Цеймах Е.А., Плетнев Г.В. и др. Использование клапанной бронхоблокации у больных с легочным кровотечением при распространенном туберкулезе. Пробл. клин. мед. 2006; 2: 61-66.

18. Valipour A., Kreuzer A., Koller H. et al. Bronchoscopy guided topical hemostatic tamponade therapy for the management of life threatening hemoptysis. Chest 2005; 127: 2113-2118.

19. Dweik R.A., Stoller J.K. Role of bronchoscopy in massive hemoptysis. Clin. Chest Med. 1999; 20: 89-105.

20. Поддубный Б.К., Белоусова Н.В., Унгиадзе Г.В. Диагностическая и лечебная эндоскопия верхних дыхательных путей. М.: Практическая медицина; 2006.

21. Яковлев В.Н., Розиков Ю.Ш., Алексеев В.Г. и др. Использование брохоскопических методов диагностики и лечения в многопрофильном стационаре. Моск. мед. журн. 2011; 2: 7-15.

22. Трахтенберг А.Х., Чиссов В.И. Клиническая онкопульмонология. М.: ГЭОТАР Медицина; 2000.

23. Jean-Babtiste E. Management of hemoptysis in the emergency department. Hosp. Physician 2005; 1: 53-59.

24. Левин А.В., Цеймах Е.А., Зимонин П.Е. Лечение легочных кровотечений. Ч. 1. Этиология, патогенез, консервативное лечение, коллапсотерапия, эндоскопические методы. Пробл. клин. мед. 2008; 1: 90-95.

25. Венцявичус В., Циценас С. Диагностика и лечение легочных кровотечений различной этиологии. Пробл. туб. и бол. легких. 2005; 1: 40-43

26. Bidwell J.L., Pachner R.W. Hemoptysis: diagnosis and management. Am. Fam. Physician. 2005; 72 (7): 1253-1260. 
27. Уткин М.М., Батыров Ф.А., Свиридов С.В.,Сергеев И.Э. Гемодинамические и клинические эффекты нитратов при легочном кровотечении. В кн.: Сборник материалов 4-й Научно-практической конференции "Диагностика и лечение нарушений регуляции сердечно-сосудистой системы". М.; 2002. 321-323.

28. Морган Д.Э.-мл., Мэгид С.М. Клиническая анестезиология: Пер. с англ. М.: Бином; 2004; кн. 3-я.

29. Endo S., Otani S., Saito N. et al. Management of massive hemoptysis in a thoracic surgical unit. Eur. J. Cardiothorac. Surg. 2003; 23: 467-472.

30. Румянцев А.Г., Бабкова Н.В., Чернов В.М. Применение рекомбинантного активированного фактора коагуляции VII в клинической практике. Обзор литературы. Гематол. и трансфузиол. 2002; 5: 36-41.

31. MacDonald J.A., Fraser J.F., Foot C.L., Tran K. Successful use of recombinant factor VII in massive hemoptysis due to community-acquired pneumonia. Chest 2006; 130: 577-579.

32. Черний В.И., Колесников А.Н., Кабанько Т.П. Современные направления в интенсивной терапии и профилактике нарушений гемостаза в медицине критических состояний (практическое руководство для врачей). Донецк: Новый мир; 2006.

33. Волошин Н.И., Петренко Д.Е., Мезенцев А.А. Сравнительный анализ применения транексамовой и аминокапроновой кислот при хирургическом лечении сколиоза. Ортопед., травматол. и протезир. 2011; 2: 87-89.

34. Шевченко Ю.Л., Стойко Ю.М., Замятин М.Н. Кровесберегающий эффект транексамовой кислоты: клиническое значение. Фарматека 2008; 16: 17-22.

35. Pereira J., Phan T. Management of bleeding in patients with advanced cancer. Oncologist 2004; 9: 561-570.

36. Мороз В.В., Марченков Ю.В., Лысенко Д.В. и др. Антибактериальная терапия нозокомиальных пневмоний, вызванных полирезистентной флорой у больных в критических состояниях. Общая реаниматол. 2007; 3: 90-94.
37. Scolapio J.S. Methods for decreasing risk of aspiration pneumonia in critically ill patients. J. Parenter. Enter. Nutr. 2002; 26: 58-61.

38. Авдеев С.Н. Аспирационная пневмония: современные подходы к диагностике и терапии. Пульмонология 2009; 2: 5-19.

39. Lenner R., Schilero G.J., Lesser M. Hemoptysis: diagnosis and management. Compr. Ther. 2002; 28: 7-14.

40. Бисенков Л.Н. Неотложная хирургия груди. СПб.: Медицина; 1995.

41. Tamashiro A., Miceli M.H., Rando C. et al. Pulmonary artery access embolization in patients with massive hemoptysis in whom bronchial and / or nonbronchial systemic artery embolization is contraindicated. Cardiovasc. Intervent. Radiol. 2008; 31 (3): 633-637.

42. Swanson K.L., Johnson C.M., Prakash U.B. et al. Bronchial artery embolization: experience with 54 patients. Chest 2002; 121: 789-795.

\section{Информация об авторах}

Яковлев Владимир Николаевич - д. М. Н., профессор, главный врач ГКБ им. С.П.Боткина ДЗ г. Москвы; тел.: (495) 945-96-40; e-mail: gkb @mosgorzdrav.ru

Марченков Юрий Викторович - Д. м. Н., руководитель клинического отдела ФГБУ "НИИ общей реаниматологии им. В.А.Неговского" РАМН, зав. отделением анестезиологии-реанимации № 18 Анестезиологореанимационного центра ГКБ им. С.П.Боткина ДЗ г. Москвы; тел.: (495)-945-35-21; e-mail: marchenkow@yandex.ru

Коржева Ирина Юрьевна - д. М. н., зав. отделением эндоскопии ГКБ им. С.П.Боткина ДЗ г. Москвы; тел.: (499) 762 62-58; e-mail: korg @rambler.ru

Алексеев Владимир Григорьевич - Д. м. Н., профессор, зам. главного врача по терапии ГКБ им. С.П.Боткина ДЗ г. Москвы; тел.: (495) 945-96-40; e-mail: gkb@mosgorzdrav.ru

Мороз Виктор Васильевич - д. М. Н., профессор, член-корреспондент РАМН, директор ФГБУ "НИИ общей реаниматологии им. В.А.Неговского" РАМН; тел.: (495) 694-27-08; e-mail: niiorramn@niiorramn.ru

Поступила 13.09.13 () Коллектив авторов, 2013 удк 616.24-005.1-07/08 